\title{
Sexual crossing of thermophilic fungus Myceliophthora heterothallica improved enzymatic degradation of sugar beet pulp
}

\author{
Maria Victoria Aguilar-Pontes ${ }^{1,2}$, Miaomiao Zhou ${ }^{1,2}$, Sjors van der Horst ${ }^{1,2}$, Bart Theelen ${ }^{3}$, Ronald P. de Vries ${ }^{1,2}$ \\ and Joost van den Brink $k^{1,2^{*}}$
}

\begin{abstract}
Background: Enzymatic degradation of plant biomass requires a complex mixture of many different enzymes. Like most fungi, thermophilic Myceliophthora species therefore have a large set of enzymes targeting different linkages in plant polysaccharides. The majority of these enzymes have not been functionally characterized, and their role in plant biomass degradation is unknown. The biotechnological challenge is to select the right set of enzymes to efficiently degrade a particular biomass. This study describes a strategy using sexual crossing and screening with the thermophilic fungus Myceliophthora heterothallica to identify specific enzymes associated with improved sugar beet pulp saccharification.
\end{abstract}

Results: Two genetically diverse M. heterothallica strains CBS 203.75 and CBS 663.74 were used to generate progenies with improved growth on sugar beet pulp. One progeny, named SBP.F1.2.11, had a different genetic pattern from the parental strains and had improved saccharification activity after the growth on $3 \%$ sugar beet pulp. The improved SBP saccharification was not explained by altered activities of the major (hemi-)cellulases. Exo-proteome analysis of progeny and parental strains after 7-day growth on sugar beet pulp showed that only 17 of the 133 secreted CAZy enzymes were more abundant in progeny SBP.F1.2.11. Particularly one enzyme belonging to the carbohydrate esterase family 5 (CE5) was more abundant in SBP.F1.2.11. This CE5-CBM1 enzyme, named as Axe1, was phylogenetically related to acetyl xylan esterases. Biochemical characterization of Axe1 confirmed de-acetylation activity with optimal activities at $75-85^{\circ} \mathrm{C}$ and pH 5.5-6.0. Supplementing Axe1 to CBS 203.75 enzyme set improved release of xylose and glucose from sugar beet pulp.

Conclusions: This study identified beneficial enzymes for sugar beet pulp saccharification by selecting progeny with improved growth on this particular substrate. Saccharification of sugar beet pulp was improved by supplementing enzyme mixtures with a previously uncharacterized CE5-CBM1 acetyl xylan esterase. This shows that sexual crossing and selection of $M$. heterothallica are the successful strategy to improve the composition of enzyme mixtures for efficient plant biomass degradation.

Keywords: Myceliophthora heterothallica, Sexual crossing, Progeny, Plant biomass, Sugar beet pulp, Saccharification, CAZy enzymes, Acetyl xylan esterase

\section{Background}

Plant biomass has an intricate composition of different polysaccharides. For that reason, enzymatic degradation

\footnotetext{
*Correspondence: joost_vandenbrink@hotmail.com

${ }^{1}$ Fungal Physiology, CBS-KNAW Fungal Biodiversity Centre, Utrecht,

The Netherlands

Full list of author information is available at the end of the article
}

of plant biomass requires a complex mixture of enzymes. Cellulolytic enzymes are at the core of plant-degrading mixtures containing different endoglucanases, cellobiohydrolases and $\beta$-glucosidases [1]. These cellulases benefit from the presence of lytic polysaccharide monooxygenases or expansin-like proteins, which attack the crystalline parts of cellulose [2,3]. Moreover, 
cellulose degradation benefits from esterases or laccases, which breaks the physical interaction between lignin and polysaccharides $[4,5]$. Other examples of enzymes improving biomass saccharification are xylanases, arabinanases and pectinases $[6,7]$. Identifying the essential enzymes for complete biomass degradation is often a trial and error method by adding individual enzymes to a core enzyme set [8]. Furthermore, the role of many carbohydrate-active enzymes (CAZy) is unknown, which leaves the majority of enzymes encoded on microbial genomes unexplored.

The filamentous fungus Myceliophthora thermophila (synonym Sporotrichum thermophile/Chrysosporium lucknowense) has shown to efficiently degrade biomass using thermostable enzymes and has more than 200 plant biomass-degrading enzymes encoded in its genome $[9,10]$. These glycoside hydrolases $(\mathrm{GH})$, polysaccharide lyases (PL), carbohydrate esterases (CE) and oxidases are covering most of the recognized fungal CAZy families [10]. $M$. thermophila is especially rich in enzymes with auxiliary activity (AA) with 22 genes belonging to CAZy family AA9 [10]. Even though the largest fraction of enzymes has only a putative function, many enzymes of $M$. thermophila have already been characterized in relation to polysaccharide degradation [11]. Moreover, Kolbusz and colleagues showed that 138 CAZy enzymes were detected in the exo-proteome when grown on a large range of plant biomasses [12]. Of these, 59 enzymes were important for growth on untreated plant biomass. This core set contained many cellulolytic enzymes such as nine AA9 monooxygenases, four GH1 and GH3 $\beta$-glucosidases, four GH6 and GH7 cellobiohydrolases, and two GH5 and GH45 endoglucanases [12]. This study is also a good example that growth on a particular biomass induces expression of specific enzymes such as esterase, xylanases and pectinases. However, a comparative study will be difficult for identifying the contribution of specific enzymes in releasing sugars from plant biomass.

The thermophile Myceliophthora heterothallica is very similar to $M$. thermophila in its morphology, physiology and phylogeny. The largest difference between the two species is the functional mating cycle of $M$. heterothallica [13]. After $2-3$ weeks at $30{ }^{\circ} \mathrm{C}, \mathrm{M}$. heterothallica isolates of opposite mating type form ascomata containing dark brown ascospores at their contact zone [14]. Interestingly, progeny of $M$. heterothallica showed to have diverse physiology with respect to biomass saccharification [9]. The ability of $M$. heterothallica to sexual reproduce essentially allows selection of progeny with improved characteristics. Sexual crossing was already previously shown to be a potentially interesting strategy to improve industrial properties of filamentous fungi [15, 16].
In the current study, $M$. heterothallica isolates CBS 203.75 and CBS 663.74 were used to produce progeny with improved growth and saccharification of sugar beet pulp (SBP). Even though these isolates have the ability to produce ascomata with viable ascospores, they are genetically very different [9]. The selection of progeny based on improved growth will select for a specialist in releasing sugars from SBP. Subsequent saccharification analysis will further select for progeny with an improved enzyme set. To identify the essential enzymes for efficient degradation of SBP, parents and progeny will be compared with respect to the extracellular proteins they produced. This study shows that combining crossing and screening with genome-wide analysis are the effective strategy to identify novel enzymes that can improve saccharification of plant biomass.

\section{Results and discussion}

\section{Sexual crosses between M. heterothallica CBS 203.75} and CBS 663.74 combined with growth screening select for strains with improved SBP saccharification

The ascospores of $M$. heterothallica isolates CBS 203.75 and CBS 663.74 were plated on agar medium with $3 \%$ SBP. After 3 days of growth at $45{ }^{\circ} \mathrm{C}$, colonies with different sizes and densities were observed (exemplified in Fig. 1a). 70 colonies with good growth were isolated to further analyse their saccharification activity against SBP. After growing the 70 progenies and parents in $2 \mathrm{ml}$ liquid SBP medium, culture supernatants were incubated for $4 \mathrm{~h}$ with a buffered SBP solution ( $\mathrm{pH}$ 5.0) before measuring the total released sugar. A large fraction of progenies had improved saccharification activities compared to parental strains CBS 203.75 and CBS 663.74 (Additional file 1: Figure S1). Remarkably, 69 of the 70 progenies had the same mating type as CBS 663.74. This might be explained by interference of some germinating conidiospores of CBS 663.74, as CBS 663.74 showed better growth on SBP and higher saccharification activities compared to CBS 203.75

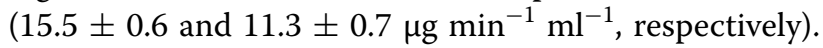
Still, one progeny with the mating type of CBS 203.75 had a saccharification activity of $20.5 \pm 2.5 \mu \mathrm{g} \mathrm{min}-1 \mathrm{ml}^{-1}$, which is respectively 1.8 -fold and 1.3 -fold higher than CBS 203.75 and CBS 663.74. Besides a higher saccharification activity, the progeny with the mating type of CBS 203.75, named SBP.F1.2.11, had also a denser colony compared to both parental strains (Fig. 1a). The genetic variation of parents and progenies was tested by amplified fragment length polymorphism (AFLP). All progenies with the mating type of CBS 663.74 had a similar AFLP banding pattern as CBS 663.74 (data not shown). However, progeny SBP.F1.2.11 had a mixed AFLP pattern of both parental strains proofing genetic content of both parents (Fig. 1b). 


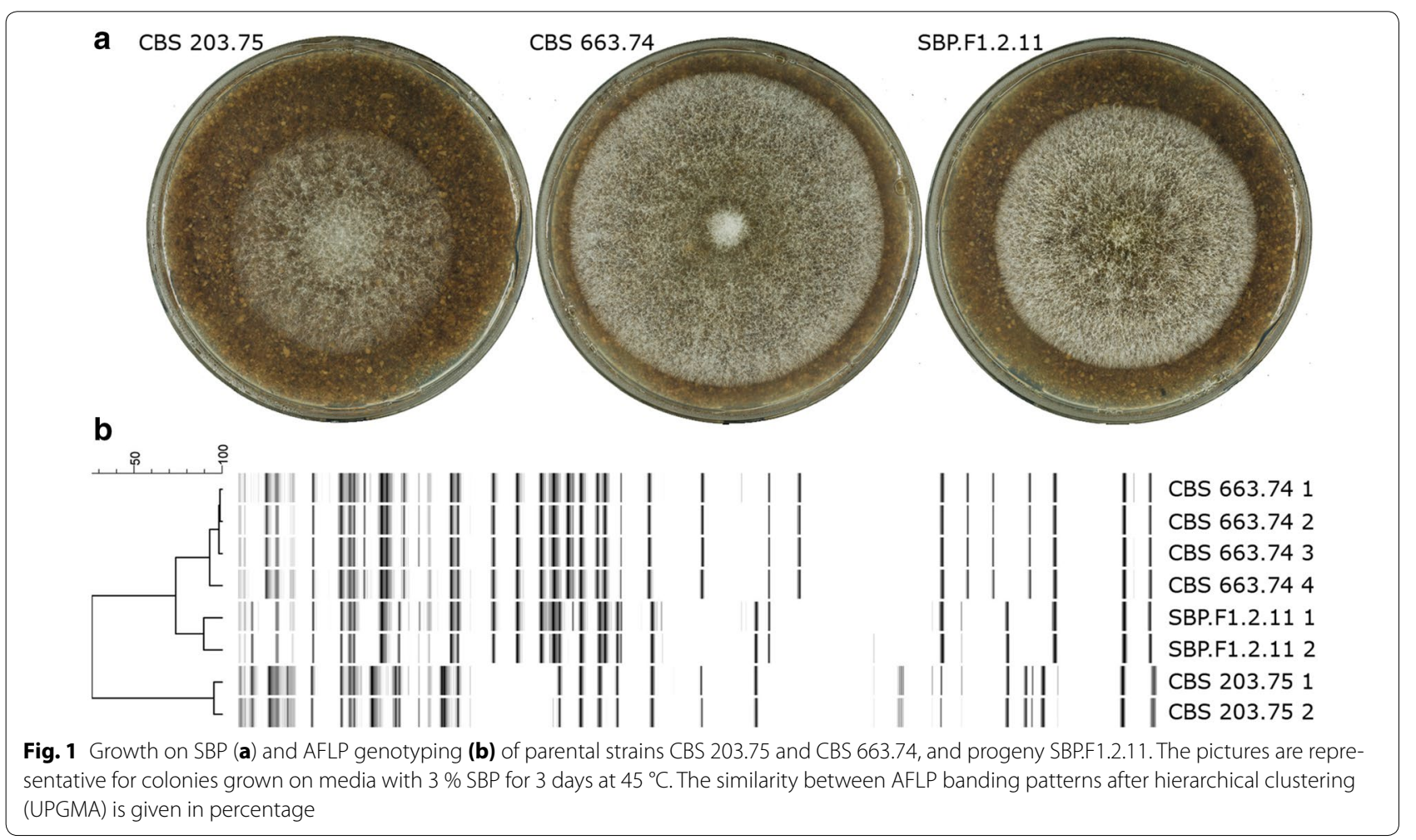

\section{Progeny SBP.F1.2.11 had improved SBP saccharification in the late phase of growth}

Before further analysis of SBP.F1.2.11, the progeny was ten times sequentially transferred on non-selective media to ensure the genomic stability of the strain. Subsequently, progeny SBP.F1.2.11 and parents CBS 203.75 and CBS 663.74 were analysed in more detail for their saccharification activity after 2,4 and 7 days growth on $3 \%$ SBP (Fig. 2). Overall, saccharification activities of CBS 203.75 and CBS 663.74 decreased over the culture time, while the activities of SBP.F1.2.11 increased during cultivation. After 2 days, CBS 203.75 and CBS 663.74 had activities of $216 \pm 2$ and $175 \pm 30 \mu \mathrm{g} \mathrm{min}{ }^{-1} \mathrm{mg}$ protein $^{-1}$, respectively. After 7 days, these activities decreased to $145 \pm 12$ and $118 \pm 2 \mu \mathrm{g} \mathrm{min}{ }^{-1} \mathrm{mg}$ protein ${ }^{-1}$, respectively. Progeny SBP.F1.2.11 had an activity of $129 \pm 3 \mu \mathrm{g} \mathrm{min}{ }^{-1} \mathrm{mg}$ protein $^{-1}$ after 2 days, and then this activity increased to $252 \pm 18 \mu \mathrm{g} \mathrm{min}^{-1} \mathrm{mg}$ protein ${ }^{-1}$ after 7 days growth. Highperformance anion exchange chromatography was performed to test the composition of the released sugars. In all saccharification samples, more than $90 \%$ of the released sugar was glucose.

\section{Improved SBP saccharification of progeny was not explained by an increased (hemi-)cellulase activity}

The large differences in SBP saccharification might be explained by altered activities of the major (hemi-)cellulases. SBP is mostly composed of cellulose and pectin

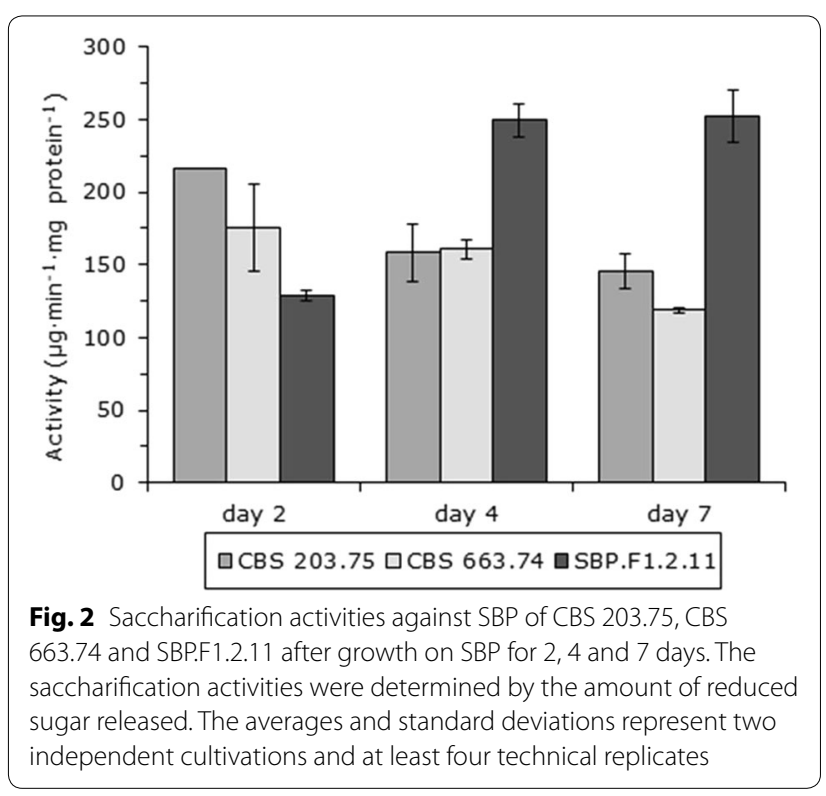

structures, but also xylose-containing structures (e.g. xylan and xyloglucan) [7]. For this reason, overall activities against cellulose, pectin and xylan substrates were measured after 2, 4 and 7 days of growth on 3 \% SBP (Fig. 3). Cellulase activities, as represented by activity against carboxymethyl cellulose, were not as different as the saccharification 


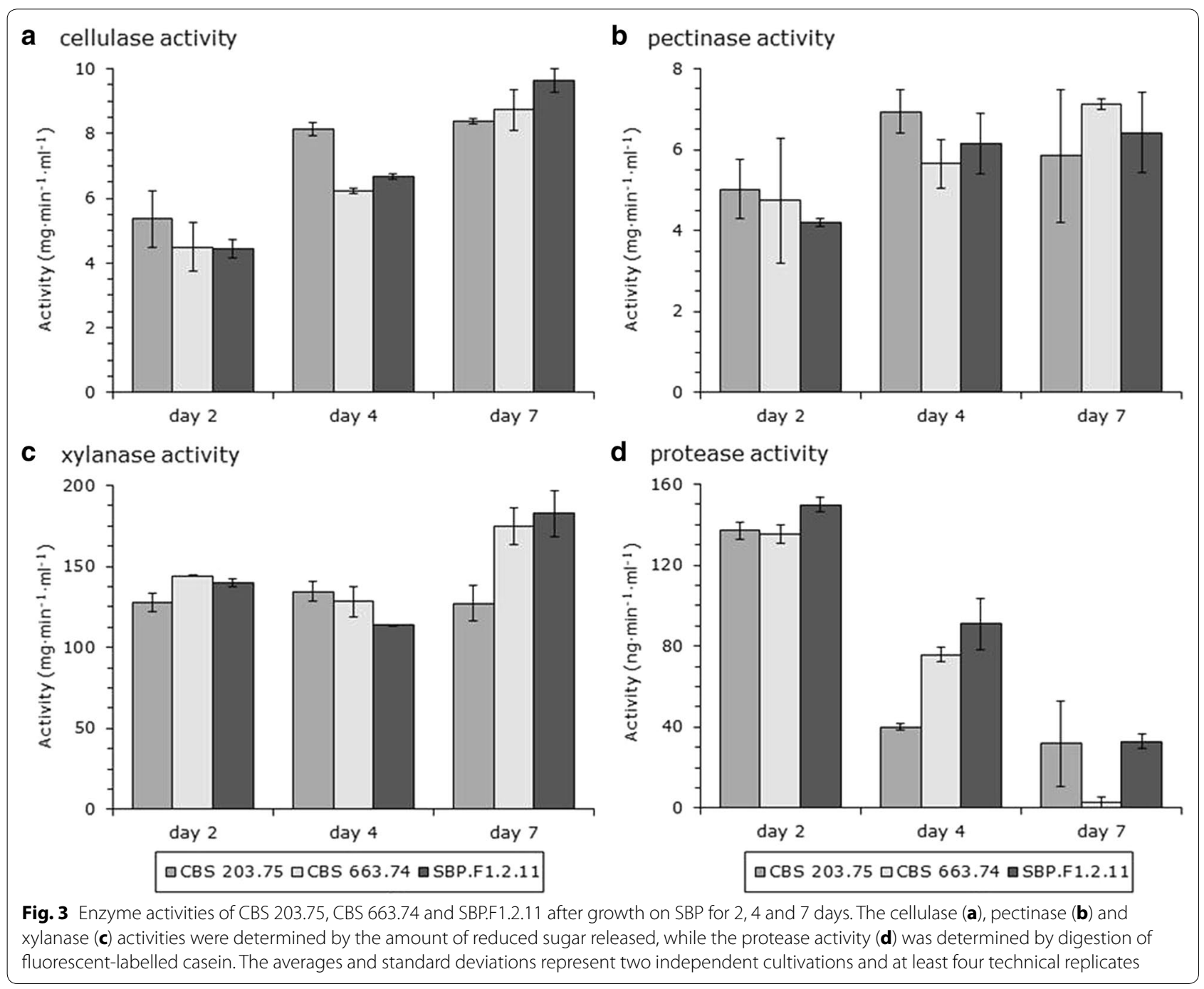

activities (Fig. 3a). The highest activities were observed after 7 days growth with small difference between parents and progeny SBP.F1.2.11. The highest activity was measured in SBP.F1.2.11 and 9.6 $\pm 0.4 \mathrm{mg} \mathrm{min}^{-1} \mathrm{ml}^{-1}$, and the lowest activity in CBS 203.75 and $8.4 \pm 0.1 \mathrm{mg} \mathrm{min}^{-1} \mathrm{ml}^{-1}$. Pectinase activities, measured against apple pectin, had no significant differences between strains with the highest activities after 4 and 7 days growth (Fig. 3b). Xylanase activities, as represented by activity against beechwood xylan, were the highest for CBS 663.74 and SBP.F1.2.11 after 7 days growth (Fig. 3c). SBP.F1.2.11 had the highest activity with $183 \pm 14 \mathrm{mg} \mathrm{min}^{-1} \mathrm{ml}^{-1}$, which was 1.4 -fold higher than CBS 203.75 with $127 \pm 11 \mathrm{mg} \mathrm{min}^{-1} \mathrm{ml}^{-1}$. Although these activities did not directly explain the higher saccharification activities, cellulolytic and xylanolytic activities were the highest for SBP.F1.2.11 after 7 days growth.
Another explanation for much higher saccharification activities of SBP.F1.2.11 after 7 days growth might be differences in protein turnover. As represented by activity against fluorescent-labelled casein, protease activities were highest after 2 days cultivation and decreased strongly over the cultivation time (Fig. 3d). This might be counterintuitive as nutrient limitation is likely to occur at the later phase of cultivation, which is known to stimulate protease activity [17]. Protease activity has also been linked to the extracellular $\mathrm{pH}$ of cultivation [18]. The extracellular $\mathrm{pH}$ of the cultivations increased gradually during the cultivation with $\mathrm{pH} 5.5$ at day 2, pH 6.5 at day 4 and $\mathrm{pH} 7.5$ at day 7. Like the measured enzyme activities, the extracellular $\mathrm{pH}$ did not explain the differences in saccharification activities as $\mathrm{pH}$ were similar between strains. 


\section{Proteomic data identified a small cluster of proteins with higher abundance in SBP.F1.2.11}

Analysing the proteome of culture filtrates will help to understand the differences in saccharification activities between SBP.F1.2.11 and parents. Before analysing their exo-proteome, the genomes of SBP.F1.2.11 and parents were sequenced, assembled and annotated. The genomes of these $M$. heterothallica strains were comparable to the genome of related species $M$. thermophila in $\mathrm{G}+\mathrm{C}$ content, size and number of genes (Table 1). As the genome of $M$. thermophila was sequenced from telomere-to-telomere, the genomes of $M$. heterothallica were expected to be a bit smaller. The smaller genome and lower gene number of the assembly of CBS 663.74 and SBP.F1.2.11 could be explained by lower sequence coverage compared to the CBS 203.75 genome. Even so, the number of CAZy proteins was similar between $M$. thermophila and the three $M$. heterothallica strains. Thirteen of the $343 \mathrm{CAZy}$ proteins of $M$. thermophila were not found in $M$. heterothallica. Only two of those proteins were shown to be expressed in M. thermophila: Mycth_90594 belonging to PL1 family and Mycth_52514 belonging to GH5 [12]. The similarity between $M$. heterothallica and $M$. thermophila was also indicated by the average sequence similarity of $96 \%$ between CAZy proteins of both species (Additional file 2: Table S1). The most remarkable difference between $M$. heterothallica strains was the absence of two (of the three) CE5 family proteins in CBS 663.74.

The exo-proteome was analysed using iTRAQ technology coupled with LC-MS/MS. A total of 133 CAZy proteins were identified in culture filtrates of the three strains after 7 days growth on SBP (Additional file 2: Table S3). This number of proteins is very similar to previous exoproteome analysis with $M$. thermophila under a wide range of conditions [12]. This study in $M$. thermophila identified 138 CAZy proteins after $48 \mathrm{~h}$ growth on 11 different plant biomasses [12]. Actually, 110 CAZy proteins were identified in both $M$. heterothallica and $M$. thermophila, which emphasize the similarity between both species.
The 133 CAZy proteins were grouped in eight clusters based on the ratio between SBP.F1.2.11 and parental strains CBS 203.75 and CBS 663.74 (Fig. 4). One-third of the proteins had a lower abundance in SBP.F1.2.11 compared to both parents (Clusters 7 and 8, 45 proteins). These clusters contained 8 of the 12 detected putative lytic polysaccharide monooxygenases belonging to the AA9 family [2]. Moreover, five putative cellobiohydrolases and endoglucanases of GH6, GH7 and GH12 family were present in clusters 7 and 8 [11]. Another large group of 31 proteins had a lower abundance in SBP.F1.2.11 compared to CBS 203.75 (Cluster 6). This cluster contained two other AA9 proteins and two GH7 proteins. Also four putative $\beta$-glucosidases of GH1 and GH3 family were present in cluster 6 . Clearly, enzymes involved in cellulose degradation were less abundant in progeny SBP.F1.2.11, which is not reflected by the measured cellulase activity against carboxymethyl cellulose. Clusters 3 and 5 contained 19 proteins with a higher abundance in SBP.F1.2.11 compared to CBS 203.75. In particular, three proteins in cluster 5 were much more abundant in SBP. F1.2.11. The two beta-glucuronidases of GH79 in cluster 5 are putatively involved in arabinogalactan degradation [19]. Cluster 2 contained 15 proteins with a higher abundance in SBP.F1.2.11 compared to CBS 203.75; however, these differences are less significant compared Clusters 3 and 5. A small group of 6 proteins had a higher abundance in SBP.F1.2.11 compared to CBS 663.74 (Cluster 4). Of the 133 detected CAZy proteins, 17 proteins had a higher abundance in SBP.F1.2.11 compared to both parents (Cluster 1).

The 17 proteins with a higher abundance in SBP.F1.2.11 were separated in three sub-clusters (Table 2). Eleven proteins were only marginally more present in SBP. F1.2.11 (Cluster 1a). This sub-cluster contained a GH74 hydrolase with putative xyloglucanase activity, a CE16 esterase with putative de-acetylation activity and a GH31 hydrolase with putative $\alpha$-xylosidase activity [20, 21]. All these activities are linked to degradation of xyloglucan

Table 1 Genome and CAZy information of Myceliophthora heterothallica

\begin{tabular}{lllll}
\hline & $\begin{array}{l}\text { M. thermophila } \\
\text { ATCC 42464 [10] }\end{array}$ & $\begin{array}{l}\text { M. heterothallica } \\
\text { CBS 203.75 }\end{array}$ & $\begin{array}{l}\text { M. heterothallica } \\
\text { CBS 663.74 }\end{array}$ & $\begin{array}{l}\text { M. heterothallica } \\
\text { SBP.F1.2.11 }\end{array}$ \\
\hline G + C content, \% & 51.4 & 52.5 & 55.9 & 55.6 \\
Genome size & $38.7 \mathrm{Mb}$ & $35.4 \mathrm{Mb}$ & $29 \mathrm{Mb}$ & $29 \mathrm{Mb}$ \\
No. of genes & 9813 & 10,061 & 8240 & 8322 \\
No. of CAZy genes & 343 & 327 & 327 & 328 \\
GH family & 186 & 179 & 180 & 179 \\
PL family & 8 & 7 & 7 & 7 \\
CE family & 27 & 25 & 23 & 25 \\
AA9 family & 23 & 22 & 22 & 22 \\
\hline
\end{tabular}




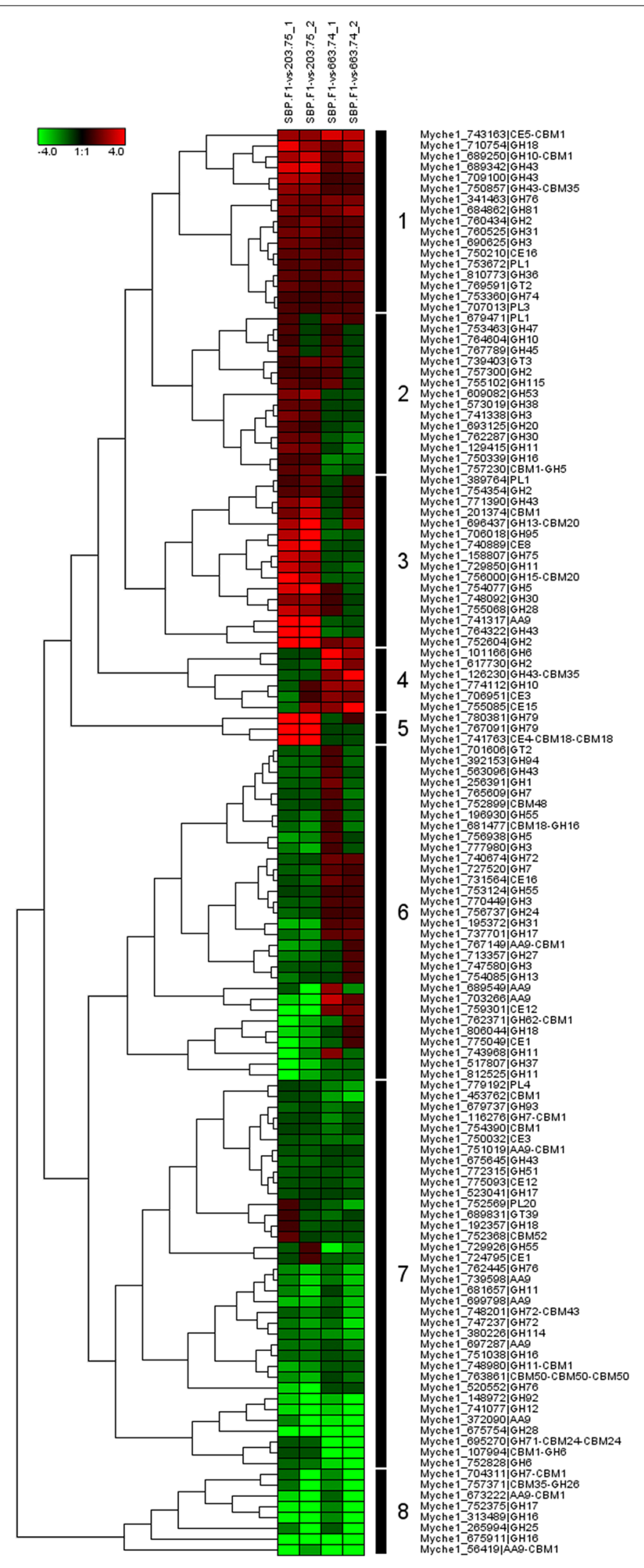


(See figure on previous page.)

Fig. 4 Hierarchical clustering of the 133 differentially expressed CAZy proteins between CBS 203.75, CBS 663.74 and SBP.F.1.2.11. The first two columns of the dendrogram display ratios between CAZymes of SBP.F.1.2.11 and CBS 203.75, while the last two columns of the dendrogram display ratios between CAZymes of SBP.F.1.2.11 and CBS 663.74. Each of the two columns represents proteomics data of an independent cultivation. Green spectra indicate proteins with decreased ratios, whereas red spectra indicate proteins with increased ratios between SBP.F.1.2.11 and the parental strain. The data can be found in Additional file 1:Table S3

structures [22]. The putative $\beta$-galactosidase activity of GH2 hydrolase can also play a role in xyloglucan degradation. Another sub-cluster of five proteins with a higher abundance in SBP.F1.2.11 were especially more present compared to CBS 203.75 (Cluster 1b). Three of those proteins belonged to the GH43 family. This family contains a wide range of activities against arabinan, arabinose, xylose and galactan residues (www.cazy.org). The remaining two proteins within this sub-cluster were a GH18 protein and a GH10 protein with a CBM1 motif. The M. thermophila homologue of this GH10-CBM1 protein has activity against non-substituted xylan chains [23]. Only one protein, belonging to the CE5 family, had a consistent higher abundance in SBP.F1.2.11 compared to both parents (Cluster 1c). CE5 proteins were reported to have esterase activities against cutin or acetylated xylan and were beneficial for saccharification of plant biomass $[4,24]$. The CE5-CBM1 protein (Myche1_743163) was most similar to acetyl xylan esterases. Like the GH10 xylanase, this CE5 protein has a CBM1 motif, which might be beneficial for degradation of xylan structure in proximity of cellulose chains [25]. Even though only $4 \%$ of SBP biomass was xylose residues (see "Methods" section), these xylan or xyloglucan chains might hinder enzymatic degradation of other polysaccharides such as cellulose and pectin [25].

\section{Acetyl xylan esterase Axe1 improved SBP saccharification}

To understand the significance of the proteomics results, contribution of the CE5-CBM1 enzyme in SBP saccharification needs to be analysed. First, the CE5CBM1 protein was phylogenetically compared to 18 characterized and 54 non-characterized CE5 proteins (Fig. 5). M. thermophila and M. heterothallica have three CE5 enzymes encoded on their genomes (M. thermophila: AEO58711.1, ADZ98863.1 and AEO60460.1).

Table 2 Hierarchical clustering in three smaller clusters $a, b$ and $c$ of the 17 more abundant CAZy proteins of SBP.F.1.2.11 compared to CBS 203.75 and CBS 663.74 (Cluster 1 within Fig. 4). The naming of the CAZy proteins refers to CBS 203.75. The data shows the fold change between SBP.F.1.2.11 and CBS 203.75, and SBP.F.1.2.11 and CBS 663.74 CAZymes. The data can also be found in Additional file 2: Table S3. Each of data point represents proteomics data of an independent cultivation

\begin{tabular}{|c|c|c|c|c|c|}
\hline CAZy protein & CAZy module(s) & SBP_1-VS-203_1 & SBP_2-VS-203_2 & SBP_1-VS-663_1 & SBP_2-VS-663_2 \\
\hline \multicolumn{6}{|l|}{ Cluster 1a } \\
\hline Myche1_750210 & CE16 & 1.44 & 1.63 & 1.24 & 1.63 \\
\hline Myche1_760434 & $\mathrm{GH} 2$ & 1.39 & 2.10 & 1.30 & 1.29 \\
\hline Myche1_690625 & $\mathrm{GH} 3$ & 1.67 & 1.63 & 1.07 & 1.17 \\
\hline Myche1_760525 & $\mathrm{GH} 31$ & 1.72 & 2.06 & 1.09 & 1.31 \\
\hline Myche1_810773 & $\mathrm{GH} 36$ & 1.48 & 1.24 & 1.56 & 1.57 \\
\hline Myche1_753360 & GH74 & 1.11 & 1.01 & 1.20 & 1.04 \\
\hline Myche1_341463 & GH76 & 1.95 & 1.65 & 1.92 & 1.88 \\
\hline Myche1_684862 & GH81 & 1.95 & 1.53 & 1.80 & 2.43 \\
\hline Myche1_769591 & GT2 & 1.55 & 1.21 & 1.27 & 1.40 \\
\hline Myche1_753672 & PL1 & 1.28 & 1.44 & 1.08 & 1.41 \\
\hline Myche1_707013 & PL3 & 1.20 & 1.06 & 1.12 & 1.23 \\
\hline \multicolumn{6}{|l|}{ Cluster 1b } \\
\hline Myche1_689250 & GH10-CBM1 & 2.60 & 3.17 & 1.39 & 2.42 \\
\hline Myche1_710754 & $\mathrm{GH} 18$ & 3.66 & 2.42 & 1.56 & 2.53 \\
\hline Myche1_689342 & $\mathrm{GH} 43$ & 3.46 & 3.57 & 1.43 & 1.72 \\
\hline Myche1_709100 & $\mathrm{GH} 43$ & 2.83 & 2.66 & 1.03 & 1.15 \\
\hline Myche1_750857 & GH43-CBM35 & 2.22 & 2.12 & 1.13 & 1.10 \\
\hline \multicolumn{6}{|l|}{ Cluster 1c } \\
\hline Myche1_743163 & CE5-CBM1 & 2.41 & 2.16 & 3.37 & 2.92 \\
\hline
\end{tabular}




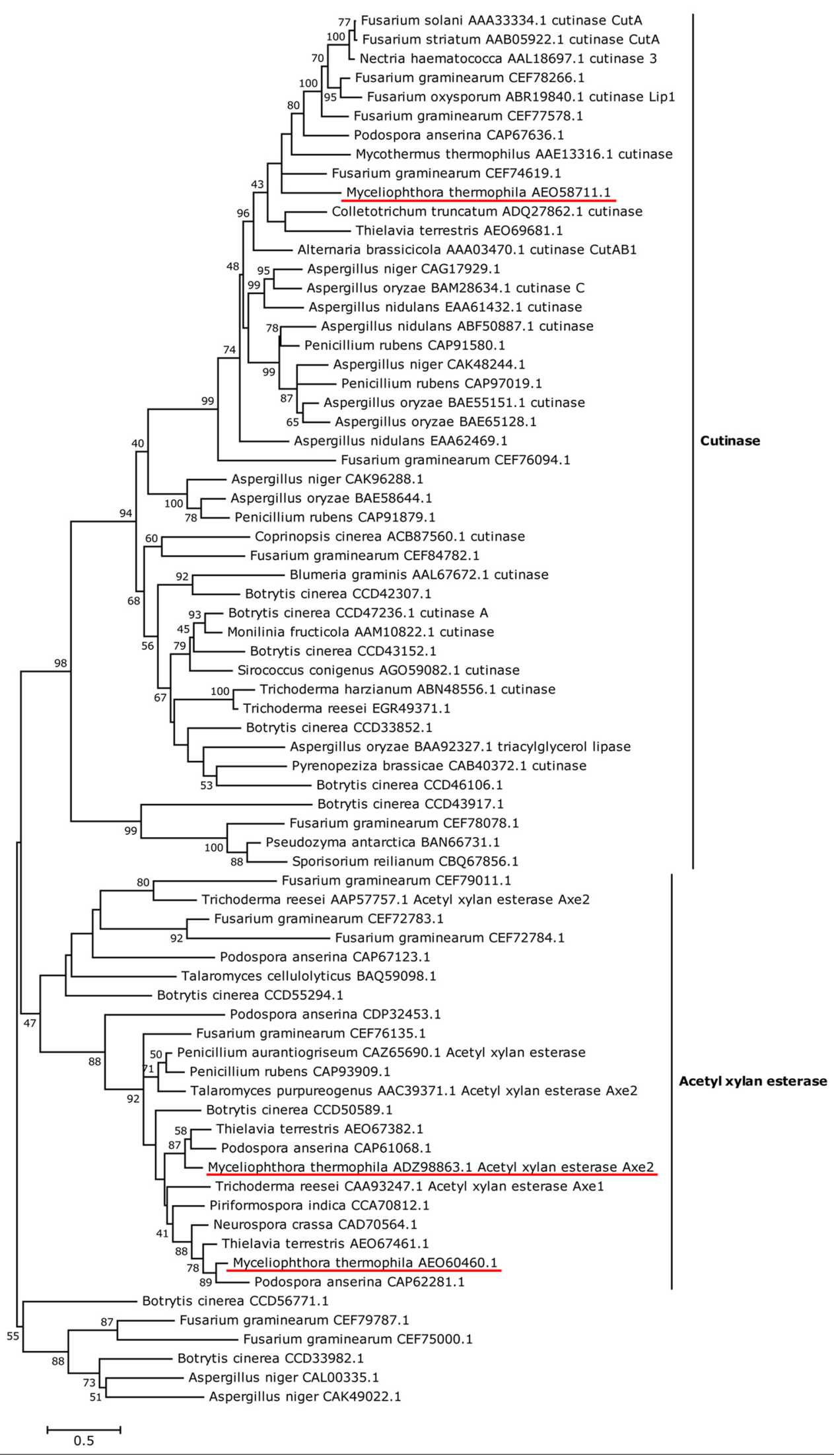


(See figure on previous page.)

Fig. 5 Phylogeny of fungal carbohydrate esterase family 5 proteins. Amino acids sequences were aligned, and phylogenetic tree was constructed, with MEGA software, version 5.0 [42]. Bootstrap values were calculated based on 1000 replicates of the data. The analysis using neighbour-joining method [43] involved 73 amino acid sequences of a total of 474 positions. All ambiguous positions were removed for each sequence pair. All sequences were obtained from CAZy pipeline (www.cazy.org)

Remarkably, M. heterothallica strain CBS 663.74 is missing two CE5 esterases, and has only the CE5-CBM1 enzyme encoded on its genome. AEO58711.1 from $M$. thermophila clustered together with characterized cutinases, while ADZ98863.1 and AEO60460.1 clustered with characterized acetyl xylan esterases. The ADZ98863.1 protein from M. thermophila ATCC 42464 is identical to the characterized acetyl xylan esterase Axe2 from $M$. thermophila $\mathrm{C} 1$ [26]. The $M$. heterothallica homologue of this protein (Mycth_49700) was not detected after growth on SBP. The CE5-CBM1 enzyme of our interest is AEO60460.1 in M. thermophila and Myche1_743163 in $M$. heterothallica. The closest characterized enzyme of AEO60460.1/Myche1_743163 is the acetyl xylan esterase CAA93247/Axe1 of Trichoderma reesei [27].

To test the influence of the putative CE5-CBM1 acetyl xylan esterase on the saccharification of SBP, the $M$. thermophila homologue was overproduced in a specially designed $M$. thermophila C1-expression host (LC strain) [28]. The CE5-CBM1 enzymes of $M$. thermophila and $M$. heterothallica differ on three amino acids: Thr31Ala, Ile33Val and Ala213Asp (Additional file 1: Figure S2). However, these amino acids are located in variable regions of CE5 enzymes and are far from the conserved CE5 catalytic residues Ser101, Asp188 and His200, and the region associated with substrate specificity $[29,30]$. The overproduced CE5-CBM1 showed good activity against methylumbelliferyl acetate substrate with the highest activity at $75-85{ }^{\circ} \mathrm{C}$ and $\mathrm{pH}$ 5.5-6.0 (Additional file 1: Figure S3). Compared to the overproduced CE5-CBM1, the background proteins of the expression host had only a low activity against methylumbelliferyl acetate. Considering phylogeny and activity, the CE5-CBM1 protein of $M$. thermophila and M. heterothallica can be named Axe1.

The effect of Axe1 on SBP saccharification was tested by supplementing enzymes of a 7-day-old culture from CBS 203.75. The released monosaccharides from SBP were quantified after $24-\mathrm{h}$ incubation at $50{ }^{\circ} \mathrm{C}$ (Fig. 6). The supplementation of Axe1 to CBS 203.75 enzymes significantly released more xylose with 1.6-fold increase to CBS 203.75 enzymes without Axe1 $(9.8 \pm 1.4 \mu \mathrm{M}$ and $6.0 \pm 0.4 \mu \mathrm{M}$, respectively). This positive effect on xylose release was not observed with the addition of background proteins of the expression host. The increased xylose release by supplementing Axe1 did support its role as acetyl xylan esterase. Sugars related to pectin structures, such as arabinose, galacturonic acid, galactose and glucuronic acid, did not show any significant difference between saccharification with and without Axe1. However, glucose release benefited from Axe1 supplementation with a 1.2-fold increase from $2786 \pm 138 \mu \mathrm{M}$ without Axe1 to $3340 \pm 274 \mu \mathrm{M}$ with Axe1. SBP saccharification might improve even further by adding the xylanase GH10-CBM1 or xyloglucan-related enzymes, which was identified in the exo-proteome analysis.

\section{Conclusions}

M. thermophila is a well-studied thermophilic fungus and industrially applied to produce homologous and heterologous enzymes [10, 28]. Like many other industrialrelevant fungi, $M$. thermophila does not have a functional sexual cycle. Even though genetic recombination can be done parasexually, sexual crossing will greatly enhance the genetic toolbox of an industrial fungus [31, 32]. The current study used sexual crossing of the related species $M$. heterothallica to increase the knowledge on more efficient enzyme mixtures for plant biomass degradation. As both species are closely related, this knowledge obtained from $M$. heterothallica enzymes can be transferred to $M$. thermophila.

Sugar beet pulp predominantly consists of cellulose and, in lesser extent, pectin and xylan structures. Due to the complex composition of this biomass, many different kinds of enzymes might be beneficial for saccharification. This makes it immediately challenging to identify essential enzymes to further improve SBP degradation. Our strategy of combining sexual crossing and screening successfully identified a previously uncharacterized acetyl xylan esterase. The addition of Axe1 to M. heterothallica enzyme mixture improved the release of xylose and glucose from SBP. More knowledge on the genetics behind Myceliophthora mating and further optimization of the crossing strategy will make $M$. heterothallica a perfect platform for research on thermophilic fungi. In the future, the same strategy can for instance be used for a wide range of substrates to identify consistent shortcomings of Myceliophthora enzyme mixtures.

\section{Methods}

\section{Strains and material}

Strains CBS 203.75, CBS 663.74 and progeny SBP. F1.2.11 (deposited as CBS 140139) are available from the 


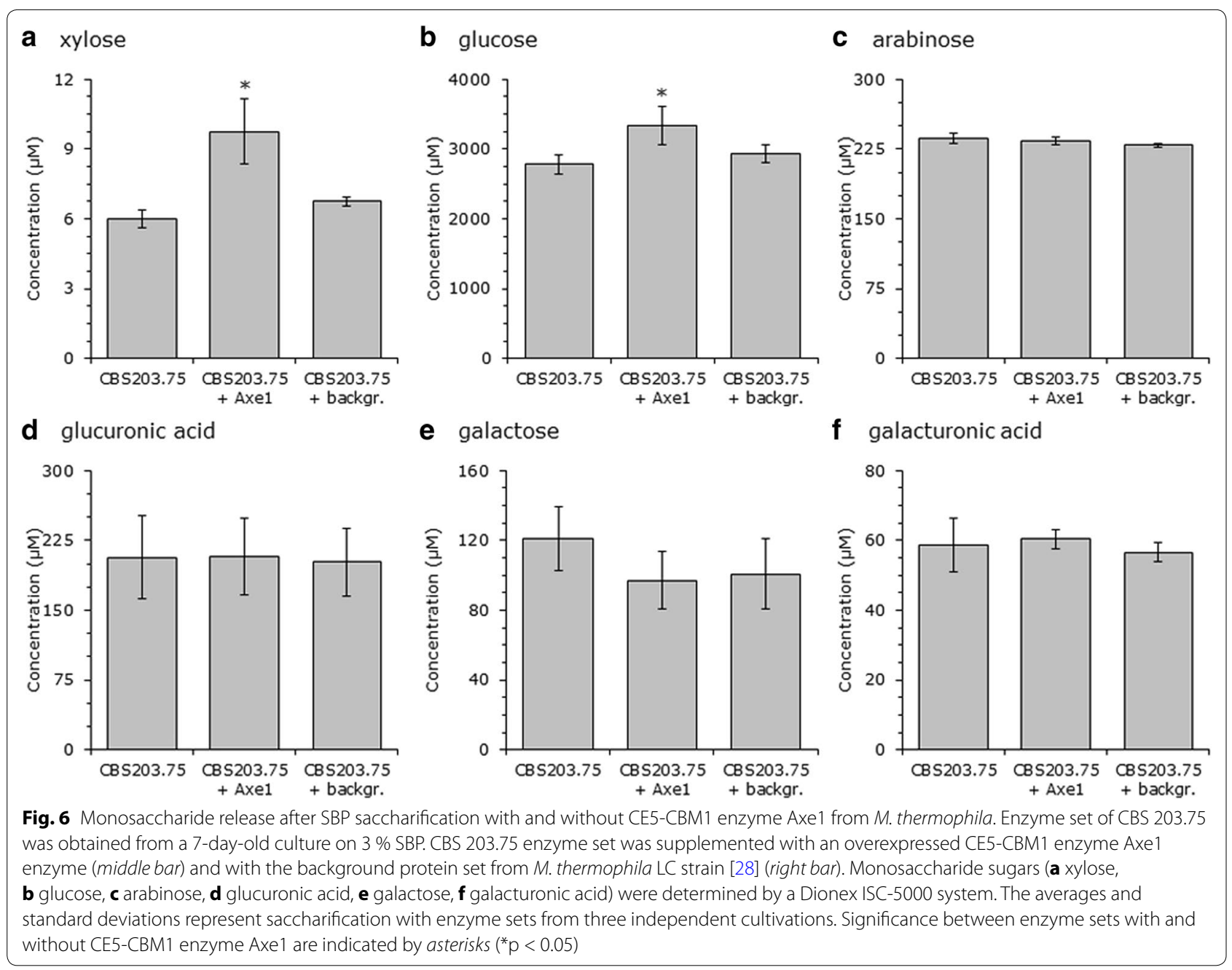

CBS-KNAW Fungal Biodiversity Centre, Utrecht, the Netherlands (www.cbs.knaw.nl).

Sugar beet pulp was mildly pretreated by exposure to $5 \%$ hydrochloric acid (performed by GreenSugar, Germany). To remove the easily accessible sugars, the pretreated sugar beet pulp were dissolved in demineralized water, autoclaved and filtered (using filter papers, quality 4, Whatman) before using them. After this washing, the sugar composition of sugar beet pulp was approximately $49 \%(\mathrm{w} / \mathrm{w})$ cellulose, $5 \%(\mathrm{w} / \mathrm{w})$ pectin and $4 \%(\mathrm{w} / \mathrm{w})$ xylan.

\section{Mating}

CBS 203.75 and CBS 663.74 were used as parental strains. Small agar plugs containing mycelium $(1 \mathrm{~mm}$ diameter) from the edge of a vigorously growing 1-dayold colony of each parent were transferred to the Petri dishes with Malt Extract Agar (MEA, BD Difco) medium and were incubated in the dark at $30{ }^{\circ} \mathrm{C}$. After two weeks, ascospores were harvested by isolating the agar with ascomata and were taken up in $5 \mathrm{ml} 10 \mathrm{mM}$ ACES ( $N$-(2-acetamido)-2-aminoethanesulfonic acid) buffer, pH 6.8, supplemented with $0.02 \%$ Tween-80 (SigmaAldrich, Zwijndrecht, The Netherlands). The ascospore solution was supplemented with approximately $1 \mathrm{~cm}^{3}$ of sterile glass beads (1:1 ratio of beads with diameters of $0.1 \mathrm{~mm}$ and $1.0 \mathrm{~mm}$ ) and homogenized by vortexing for $10 \mathrm{~min}$. The mycelial debris was removed by filtration through sterile glass wool. The ascospores $\left(>1 \times 10^{3}\right.$ per $0.1 \mathrm{ml}$ ) were cultured on minimal media [33] containing $1.5 \%$ agar and $3 \%$ sugar beet pulp for 3 days at $45^{\circ} \mathrm{C}$.

\section{Screening of progeny for saccharification activity}

Progeny from 70 colonies were tested for saccharification activity against sugar beet pulp. A conidiospore solution of each progeny $\left(1 \times 10^{6}\right.$ spore per $\left.\mathrm{ml}\right)$ was used to inoculate $2 \mathrm{ml}$ minimal media with $3 \%$ sugar beet pulp in a 12-well plate (Greiner, Germany). The plates were sealed with a gas permeable sealing membrane (Diversified Biotech, MA, USA). Cultures were centrifuged 
after 3 -days cultivation at $45{ }^{\circ} \mathrm{C}$, and supernatants were used to measure saccharification activities. $50 \mu \mathrm{l}$ culture supernatant was added to $150 \mu \mathrm{l}$ of $3 \%$ sugar beet pulp in $50 \mathrm{mM}$ sodium acetate ( $\mathrm{pH} 5.0$ ), and incubated for $4 \mathrm{~h}$ at $70{ }^{\circ} \mathrm{C}$ and $500 \mathrm{rpm}$. The total amount of released sugar was estimated using 3,5-dinitrosalicylic acid (DNS) assay [9]. All cultivations and subsequent analysis were at least done in triplicate.

\section{Genotyping}

Mating type of progeny was identified by amplifying the mating region mat $a-1$ and mat $A-3$. The mat $a-1$ region was partially amplified using forward primer GCTTCCGCATGCAATCGTTTTT and reverse primer ACGGGTGATGTCGCTGTTAGGTAT. The mat $A-3$ region was partially amplified using forward primer GAGAGGAAGCTGAGGGTTACG and reverse primer GTTCGCGCATTGTCAGCACT.

The overall genotype of CBS 203.75 and CBS 663.74 and their progenies was determined using Amplified Fragment Length Polymorphism (AFLP) fingerprint analysis, as described previously by Boekhout et al. [34].

\section{Phenotypic analysis}

Strains CBS 203.75, CBS 663.74 and SBP.F1.2.11 were pre-grown on MEA medium before conidiospores were isolated in $10 \mathrm{mM}$ ACES buffer. The spore solution $\left(1 \times 10^{6}\right.$ spore per $\left.\mathrm{ml}\right)$ was used to inoculate $50 \mathrm{ml} \mathrm{min}$ imal media with $3 \%$ sugar beet pulp in a 250 -ml shake flask. The cultures were grown for 7 days at $45{ }^{\circ} \mathrm{C}$ and $250 \mathrm{rpm}$, and samples were taken at days 2, 4 and 7 for physiological analysis of the culture supernatant.

The saccharification activity was measured using $50 \mu \mathrm{l}$ culture supernatant and $150 \mu \mathrm{l}$ of $3 \%$ sugar beet pulp in $50 \mathrm{mM}$ sodium acetate ( $\mathrm{pH}$ 5.0). The samples were incubated in microtiter plates for $4 \mathrm{~h}$ at $70{ }^{\circ} \mathrm{C}$ and $500 \mathrm{rpm}$. The total amount of released sugar was estimated using 3,5-dinitrosalicylic acid (DNS) assay [9]. Furthermore, the released solubilized monosaccharides (arabinose, galactose, glucose, xylose, galacturonic acid and glucuronic acid) were quantified using high-performance anion exchange chromatography with a Dionex ISC5000 system, which is equipped with a CarboPac PA1 (250 mm $\times 4 \mathrm{~mm}$ i.d.) column (Dionex, Sunnyvale, California, USA) and a pulsed amperometric detector (HPAEC-PAD).

Cellulase, pectinase and xylanase activities were determined against carboxymethyl cellulose, apple pectin and beechwood xylan (all Sigma-Aldrich, Germany), respectively. The assays contained a total volume of $200 \mu \mathrm{L}$ using $10-50 \mu \mathrm{L}$ of culture filtrates and $150 \mu \mathrm{L}$ of $1 \%$ substrate in $50 \mathrm{mM}$ sodium acetate $\mathrm{pH}$ 5.0. The samples were incubated in microtiter plates for $30-120 \mathrm{~min}$ at $70{ }^{\circ} \mathrm{C}$ and
$500 \mathrm{rpm}$. Subsequently, $100 \mu \mathrm{L}$ of supernatant was mixed with $150 \mu \mathrm{L}$ 3,5-dinitrosalicylic acid (DNS) solution. After an incubation of $25 \mathrm{~min}$ at $95^{\circ} \mathrm{C}$, absorbance was measured at $540 \mathrm{~nm}$ in a microtiter platereader (FLUOstar OPTIMA, BMG LabTech). The activities were calculated using a standard curve ranging from 0 to $2 \mathrm{~g} \mathrm{~L}^{-1}$ glucose. Protein concentrations were determined using Coomassie (Bradford) Protein Assay Kit (no. 23200, Pierce).

\section{Genome sequencing, assembly and annotation}

CBS 203.75 was sequenced using Illumina technology by the Joint Genome Institute (JGI) and assembled using the standard JGI pipeline for draft fungal sequences (e.g. [10]). CBS 663.74 and SBP.F1.2.11 were also sequenced using Illumina technology, but assembly and annotation were performed in-house using ClcBio (CLC Genomics Workbench, Denmark) and Augustus v3.0.2 [35], respectively. The CAZy enzymes [36] were identified using blastp (e-value $<1 \times 10^{-40}$ ) against the database of Myceliophthora thermophila [10] (Additional file 2).

\section{Proteomic preparation, analysis and quantification}

Quantitative proteomics were performed using iTRAQ technology coupled with 2D-nanoLC-nano-ESI-MS/ MS to examine the difference of protein profiles [37, 38]. Proteins $(100 \mu \mathrm{g})$ were digested with trypsin (Trypsin Gold, Promega, Madison, USA) at a trypsin/protein ratio of $1: 20$ for $4 \mathrm{~h}$ at $37{ }^{\circ} \mathrm{C}$ followed by another round of digestion at the same trypsin/protein ratio for $8 \mathrm{~h}$ at $37^{\circ} \mathrm{C}$. Digested samples were labelled with 8-plex iTRAQ reagents according to the manufacturer's instructions (Applied Biosystems, California, USA).

The labelled samples were pooled and resolved into 12 fractions using an Ultremex SCX column containing $5-\mu \mathrm{m}$ particles (Phenomenex, USA). The eluted fractions were then desalted using a Strata X C18 column (Phenomenex, USA) and dried under vacuum. The final average peptide concentration in each fraction was about $0.5 \mu \mathrm{g} \mu \mathrm{L}^{-1}$. Dried peptides were stored at $-80{ }^{\circ} \mathrm{C}$ before MS analysis.

A splitless nanoACQuity (Waters, USA) system coupled with Triple TOF was used for analytical separation. Microfluidic traps and nanofluidic columns packed with Symmetry C18 $(5 \mu \mathrm{m}, 75 \mu \mathrm{m} \times 20 \mathrm{~mm})$ were utilized for online trapping and desalting, and nanofluidic columns packed with BEH130 C18 $(1.7 \mu \mathrm{m}, 100 \mu \mathrm{m} \times 100 \mathrm{~mm})$ were employed in analytical separation. Solvents purchased from Thermo Fisher Scientific (USA) were composed of water/acetonitrile/formic acid (A: 98/2/0.1\%; B: $5 / 95 / 0.1 \%)$. A portion of a $2.25 \mu \mathrm{g}(9 \mu \mathrm{L})$ sample was loaded, and trapping and desalting were carried out at $8 \mu \mathrm{L} \mathrm{min}{ }^{-1}$ for $4 \mathrm{~min}$ with $99 \%$ solvent A. At a flow rate of $300 \mathrm{~nL} \mathrm{~min}{ }^{-1}$, analytical separation was established 
by a linear gradient from 2 to $35 \%$ solvent B for $40 \mathrm{~min}$. Following the peptide elution window, the gradient was linear increased to $80 \%$ solvent B in 5 min and maintained for $4 \mathrm{~min}$. Initial chromatographic conditions were restored in $1 \mathrm{~min}$.

The peptides were subjected to nano-electrospray ionization followed by tandem mass spectrometry (MS/MS) in a Q Exactive Mass Spectrometer (ThermoFisher Scientific, San Jose, USA). The detection settings were according to [38].

The 2.3.02 version of Mascot software (Matrix Science) was used to simultaneously identify and quantify proteins. In this version, only unique peptides used for protein quantification were chosen to quantify proteins more precisely. Searches were made against the three $M$. heterothallica protein databases. Spectra from the 12 fractions were combined into one MGF (Mascot generic format) file after the raw data were loaded, and the MGF file was searched. The search parameter settings in Mascot software were according to [38].

The mass spectrometry proteomics data have been deposited to the ProteomeXchange Consortium [39] via the PRIDE partner repository with the dataset identifier PXD003130.

\section{Phylogeny of CE5 proteins}

Fungal CE5 proteins present at the Carbohydrate-Active enZYmes Database (www.cazy.org) were downloaded and aligned with MAFFT version 7 [40]. The construction of parsimonious consensus tree was performed according to van den Brink et al. [14].

\section{CE5-CBM1 protein production}

The CE5-CBM1 protein of $M$. thermophila C1 (identical to Mycth_2066457) was overproduced in a specially designed $M$. thermophila C1-expression host (LC strain) [28]. Both, the 'empty' expression host strain and the strain with the CE5-CBM1 protein were grown in fermenters of 2 litres in volume on mineral medium containing glucose, ammonium sulphate and appropriate microelements. The cells were cultivated as described in $[28,41]$. The samples of the 'empty' expression host strain contained $13.7 \%$ protein $(\mathrm{w} / \mathrm{w})$ and will be referred to as the background sample. The sample of the strain with the overproduced CE5-CBM1 protein contained $44.2 \%$ protein $(w / w)$. Approximately half of the protein in this sample were the CE5-CBM1 protein. All derived biochemical analysis of the CE5-CBM1 protein sample were compared to the background sample.

\section{Acetyl esterase activity}

Acetyl esterase activity of the CE5-CBM1 protein was measured against 4-methylumbelliferyl acetate (M0883,
Sigma-Aldrich, Zwijndrecht, The Netherlands). The assay contained $10 \mu \mathrm{L}$ of $40 \mathrm{ng}$ protein $\mathrm{mL}^{-1}$ sample, $10 \mu \mathrm{L}$ of $100 \mu \mathrm{M}$ substrates and $80 \mu \mathrm{L}$ of $25 \mathrm{mM}$ sodium acetate, $\mathrm{pH}$ 5.0. Change in fluorescence was measured at excitation of $360 \mathrm{~nm}$ and emission of $500 \mathrm{~nm}$ in a microtiter platereader (FLUOstar OPTIMA, BMG LabTech). Temperature optimum was determined by 5 or $10 \mathrm{~min}$ incubation on a heating thermomixer (Ditabis, Germany) at $30{ }^{\circ} \mathrm{C}$ till $90{ }^{\circ} \mathrm{C}$. $\mathrm{pH}$ optimum was determined by a $10 \mathrm{~min}$ incubation at $70{ }^{\circ} \mathrm{C}$ using $0.4 \mathrm{M}$ Britton-Robinson buffer in a $\mathrm{pH}$ range between 2 and 12 .

\section{SBP saccharification using CE5-CBM1 protein}

Strain CBS 203.75 was grown for 7 days on minimal media with $3 \% \mathrm{SBP}$ at $45^{\circ} \mathrm{C}$ and $250 \mathrm{rpm}$. Of this culture, $1 \mathrm{~mL}$ of supernatant (total of approximately $262 \mu \mathrm{g}$ ) was used to incubate with $9 \mathrm{~mL} 3 \% \mathrm{SBP}$ in $25 \mathrm{mM}$ sodium acetate, $\mathrm{pH}$ 5.0. Incubations were performed in $50 \mathrm{~mL}$ flasks at $50{ }^{\circ} \mathrm{C}$ and $250 \mathrm{rpm}$ for $24 \mathrm{~h}$. Part of the flasks were supplemented with $500 \mu \mathrm{L}$ of $40 \mathrm{ng} \mathrm{mL}^{-1}$ CE5CBM1 protein sample or background sample (total of $0.02 \mu \mathrm{g}$ ). The solubilized monosaccharides (arabinose, galactose, glucose, xylose, galacturonic acid and glucuronic acid) were quantified using a Dionex ISC-5000 system. The saccharification assays were performed with enzyme sets from three independent cultivations of CBS 203.75.

\section{Additional files}

Additional file 1. Pdf file with three additional figures S1, S2, and S3. Figure S1 shows the saccharification activities against sugar beet pulp of 70 progenies and their M. heterothallica parents CBS 203.75 and CBS 663.74. The activities were measured using culture filtrates of a three-dayold culture on sugar beet pulp medium. Figure S2 shows alignment of the protein sequences of Axe1 from M. thermophila and M. heterothallica. Figure S3 shows temperature and $\mathrm{pH}$ profiles of the de-acetylating activity of CE5-CBM1 enzyme Axe1 of M. thermophila C1.

Additional file 2. Excel file with three tables S1, S2, and S3. Table S1 contains blast results of CAZy protein sequences of $M$. thermophila against the protein databases of M. heterothallica CBS 203.75, CBS 663.74, and SBP.F1.2.11. Table S2 contains protein sequences of CAZy proteins in $M$. heterothallica CBS 203.75, CBS 663.74, and SBP.F1.2.11. Table S3 contains the protein ratio of detected CAZy proteins between CBS 203.75 and SBP. F1.2.11, and CBS 663.74 and SBP.F1.2.11. The proteomics data have been deposited to the ProteomeXchange Consortium with the dataset identifier PXD003130.

\section{Abbreviations}

SBP: sugar beet pulp; CAZy: carbohydrate-active enzymes; GH: glycoside hydrolases; PL: polysaccharide lyases; CE: carbohydrate esterases (CE); AA: auxiliary activity; AFLP: amplified fragment length polymorphism; CBM: carbohydrate-binding module.

\section{Authors' contributions}

MVAP and MZ helped designing the experiments, performed the genome and exo-proteome analysis, and helped to draft the manuscript. SvdH performed the experiments related to sexual crossing and screening of $M$. heterothallica, 
and helped to revise the manuscript. BT designed, performed and interpreted the AFLP experiment, and helped to draft the manuscript. RPdV helped designing the experiments, and reviewed and commented on the manuscript. JvdB designed the study, performed the experiments, analysed the results and drafted the manuscript. All authors read and approved the final form of the manuscript.

\section{Author details}

${ }^{1}$ Fungal Physiology, CBS-KNAW Fungal Biodiversity Centre, Utrecht, The Netherlands. ${ }^{2}$ Fungal Molecular Physiology, Utrecht University, Utrecht, The Netherlands. ${ }^{3}$ Yeast and Basidiomycete Research, CBS-KNAW Fungal Biodiversity Centre, Utrecht, The Netherlands.

\section{Acknowledgements}

JvdB was supported by Grant 12468 of the Dutch Technology Foundation STW, which is part of the Netherlands Organisation for Scientific Research (NWO), and which is partly funded by the Ministry of Economic Affairs. MVAP was supported by a Grant of the Dutch Technology Foundation STW of NWO and the Technology Program of the Ministry of Economic Affairs 016.130.609 to RPdV. GreenSugar is gratefully acknowledged for the provision of the pretreated sugar beet pulp. Dyadic is gratefully acknowledged for the provision of the CBS 663.74 genome sequence and overexpressed CE5-CBM1 protein.

\section{Competing interests}

The authors declare that they have no competing interests.

Received: 4 November 2015 Accepted: 10 February 2016

Published online: 20 February 2016

\section{References}

1. Rosgaard L, Pedersen S, Langston J, Akerhielm D, Cherry JR, Meyer AS. Evaluation of minimal Trichoderma reesei cellulase mixtures on differently pretreated Barley straw substrates. Biotechnol Prog. 2007;23:1270-6.

2. Eibinger M, Ganner T, Bubner P, Rošker S, Kracher D, Haltrich D, Ludwig R, Plank H, Nidetzky B. Cellulose surface degradation by a lytic polysaccharide monooxygenase and its effect on cellulase hydrolytic efficiency. J Biol Chem. 2014;289:35929-38.

3. Gourlay K, Hu J, Arantes V, Andberg M, Saloheimo M, Penttilä M, Saddler J. Swollenin aids in the amorphogenesis step during the enzymatic hydrolysis of pretreated biomass. Bioresour Technol. 2013;142:498-503.

4. Várnai $A$, Costa TH, Faulds CB, Milagres AM, Siika-Aho M, Ferraz A. Effects of enzymatic removal of plant cell wall acylation (acetylation, p-coumaroylation, and feruloylation) on accessibility of cellulose and xylan in natural (non-pretreated) sugar cane fractions. Biotechnol Biofuels. 2014;7:153.

5. Kudanga T, Le Roes-Hill M. Laccase applications in biofuels production: current status and future prospects. Appl Microbiol Biotechnol. 2014;98:6525-42.

6. Viikari L, Alapuranen M, Puranen T, Vehmaanperä J, Siika-Aho M. Biofuels, vol. 108. Berlin: Springer; 2007

7. Zhang J, Pakarinen A, Viikari L. Synergy between cellulases and pectinases in the hydrolysis of hemp. Bioresour Technol. 2013;129:302-7.

8. Banerjee G, Car S, Scott-Craig JS, Borrusch MS, Walton JD. Rapid optimization of enzyme mixtures for deconstruction of diverse pretreatment/ biomass feedstock combinations. Biotechnol Biofuels. 2010;3:22.

9. Van den Brink J, van Muiswinkel GCJ, Theelen B, Hinz SWA, de Vries RP. Efficient plant biomass degradation by thermophilic fungus Myceliophthora heterothallica. Appl Environ Microbiol. 2013;79:1316-24.

10. Berka RM, Grigoriev IV, Otillar R, Salamov A, Grimwood J, Reid I, Ishmael N, John T, Darmond C, Moisan M-C, Henrissat B, Coutinho PM, Lombard V, Natvig DO, Lindquist E, Schmutz J, Lucas S, Harris P, Powlowski J, Bellemare A, Taylor D, Butler G, de Vries RP, Allijn IE, van den Brink J, Ushinsky S, Storms R, Powell AJ, Paulsen IT, Elbourne LDH, et al. Comparative genomic analysis of the thermophilic biomass-degrading fungi Myceliophthora thermophila and Thielavia terrestris. Nat Biotechnol. 2011;29:922-7.

11. Karnaouri A, Topakas E, Antonopoulou I, Christakopoulos P. Genomic insights into the fungal lignocellulolytic system of Myceliophthora thermophila. Front Microbiol. 2014;5:281.
12. Kolbusz MA, Di Falco M, Ishmael N, Marqueteau S, Moisan M-C, da Silva Baptista C, Powlowski J. Transcriptome and exoproteome analysis of utilization of plant-derived biomass by Myceliophthora thermophila. Fungal Genet Biol. 2014;72:10-20.

13. Von Klopotek A. Thielavia heterothallica spec. nov. (Abb. 1) Status conidialis: Chrysosporium thermophilum (Apinis) von Klopotek. Arch Microbiol. 1976;107:223-4

14. Van den Brink J, Samson RA, Hagen F, Boekhout T, de Vries RP. Phylogeny of the industrial relevant, thermophilic genera Myceliophthora and Corynascus. Fungal Divers. 2012;52:10.

15. Böhm J, Hoff B, O'Gorman CM, Wolfers S, Klix V, Binger D, Zadra I, Kürnsteiner H, Pöggeler S, Dyer PS, Kück U. Sexual reproduction and matingtype-mediated strain development in the penicillin-producing fungus Penicillium chrysogenum. Proc Natl Acad Sci USA. 2013;110:1476-81.

16. Chuang Y-C, Li W-C, Chen C-L, Hsu PW-C, Tung S-Y, Kuo H-C, Schmoll M, Wang T-F. Trichoderma reesei meiosis generates segmentally aneuploid progeny with higher xylanase-producing capability. Biotechnol Biofuels. 2015:8:30.

17. White $S$, Mclntyre M, Berry DR, McNeil B. The autolysis of industrial filamentous fungi. Crit Rev Biotechnol. 2002;22:1-14.

18. O'Donnell D, Wang L, Xu J, Ridgway D, Gu T, Moo-Young M. Enhanced heterologous protein production in Aspergillus niger through $\mathrm{pH}$ control of extracellular protease activity. Biochem Eng J. 2001;8:187-93.

19. Konishi T, Kotake T, Soraya D, Matsuoka K, Koyama T, Kaneko S, Igarashi K, Samejima M, Tsumuraya Y. Properties of family 79 beta-glucuronidases that hydrolyze beta-glucuronosyl and 4-O-methyl-beta-glucuronosyl residues of arabinogalactan-protein. Carbohydr Res. 2008;343:1191-201.

20. Koutaniemi S, van Gool MP, Juvonen M, Jokela J, Hinz SW, Schols HA, Tenkanen M. Distinct roles of carbohydrate esterase family CE16 acetyl esterases and polymer-acting acetyl xylan esterases in xylan deacetylation. J Biotechnol. 2013;168:684-92.

21. Hasper AA, Dekkers E, van Mil M, van de Vondervoort PJI, de Graaff LH. EglC, a new endoglucanase from Aspergillus niger with major activity towards xyloglucan. Appl Environ Microbiol. 2002;68:1556-60.

22. Van den Brink J, de Vries RP. Fungal enzyme sets for plant polysaccharide degradation. Appl Microbiol Biotechnol. 2011;91:1477-92.

23. Van Gool MP, van Muiswinkel GCJ, Hinz SWA, Schols HA, Sinitsyn AP, Gruppen H. Two GH10 endo-xylanases from Myceliophthora thermophila $\mathrm{C} 1$ with and without cellulose binding module act differently towards soluble and insoluble xylans. Bioresour Technol. 2012;119:123-32.

24. Neumüller KG, Streekstra H, Gruppen H, Schols HA. Trichoderma longibrachiatum acetyl xylan esterase 1 enhances hemicellulolytic preparations to degrade corn silage polysaccharides. Bioresour Technol. 2014;163:64-73.

25. Inoue H, Kishishita S, Kumagai A, Kataoka M, Fujii T, Ishikawa K. Contribution of a family 1 carbohydrate-binding module in thermostable glycoside hydrolase 10 xylanase from Talaromyces cellulolyticus toward synergistic enzymatic hydrolysis of lignocellulose. Biotechnol Biofuels. 2015:8:77.

26. Pouvreau L, Jonathan MC, Kabel MA, Hinz SWA, Gruppen H, Schols HA. Characterization and mode of action of two acetyl xylan esterases from Chrysosporium lucknowense C1 active towards acetylated xylans. Enzyme Microb Technol. 2011;49:312-20.

27. Margolles-Clark E, Tenkanen M, Söderlund H, Penttilä M. Acetyl xylan esterase from Trichoderma reesei contains an active-site serine residue and a cellulose-binding domain. Eur J Biochem. 1996;237:553-60.

28. Visser H, Joosten V, Punt PJ, Gusakov AV, Olson PT, Joosten R, Bartels J, Visser J, Sinitsyn AP, Emalfarb MA, Verdoes JC, Wery J. Development of a mature fungal technology and production platform for industrial enzymes based on a Myceliophthora thermophila isolate, previously known as Chrysosporium lucknowense C1. Ind Biotechnol. 2011;7:9.

29. Hakulinen N, Tenkanen M, Rouvinen J. Three-dimensional structure of the catalytic core of acetylxylan esterase from Trichoderma reesei: insights into the deacetylation mechanism. J Struct Biol. 2000;132:180-90.

30. Colombres M, Garate JA, Lagos CF, Araya-Secchi R, Norambuena P, Quiroz S, Larrondo L, Pérez-Acle T, Eyzaguirre J. An eleven amino acid residue deletion expands the substrate specificity of acetyl xylan esterase II (AXE II) from Penicillium purpurogenum. J Comput Aided Mol Des. 2008;22:19-28.

31. Swart K, Debets AJ, Bos CJ, Slakhorst M, Holub EF, Hoekstra RF. Genetic analysis in the asexual fungus Aspergillus niger. Acta Biol Hung. 2001:52:335-43. 
32. Seidl V, Seibel C, Kubicek CP, Schmoll M. Sexual development in the industrial workhorse Trichoderma reesei. Proc Natl Acad Sci USA. 2009;106:13909-14.

33. De Vries RP, Burgers $K$, van de Vondervoort PJI, Frisvad JC, Samson RA, Visser J. A new black Aspergillus species, A. vadensis, is a promising host for homologous and heterologous protein production. Appl Environ Microbiol. 2004;70:3954-9.

34. Boekhout T, Theelen B, Diaz M, Fell JW, Hop WC, Abeln EC, Dromer F, Meyer W. Hybrid genotypes in the pathogenic yeast Cryptococcus neoformans. Microbiology. 2001;147:891-907.

35. Stanke M, Steinkamp R, Waack S, Morgenstern B. AUGUSTUS: a web server for gene finding in eukaryotes. Nucleic Acids Res. 2004;32:W309-12.

36. Lombard V, Bernard T, Rancurel C, Brumer H, Coutinho PM, Henrissat B. A hierarchical classification of polysaccharide lyases for glycogenomics. Biochem J. 2010;432:437-44.

37. Unwin RD, Griffiths JR, Whetton AD. Simultaneous analysis of relative protein expression levels across multiple samples using iTRAQ isobaric tags with 2D nano LC-MS/MS. Nat Protoc. 2010;5:1574-82

38. Wang J, Mei H, Zheng C, Qian H, Cui C, Fu Y, Su J, Liu Z, Yu Z, He J. The metabolic regulation of sporulation and parasporal crystal formation in
Bacillus thuringiensis revealed by transcriptomics and proteomics. Mol Cell Proteomics. 2013;12:1363-76.

39. Vizcaíno JA, Deutsch EW, Wang R, Csordas A, Reisinger F, Ríos D, Dianes JA, Sun Z, Farrah T, Bandeira N, Binz PA, Xenarios I, Eisenacher M, Mayer G, Gatto L, Campos A, Chalkley RJ, Kraus HJ, Albar JP, Martinez-Bartolomé S, Apweiler R, Omenn GS, Martens L, Jones AR, Hermjakob H. ProteomeXchange provides globally co-ordinated proteomics data submission and dissemination. Nature Biotechnol. 2014;30:223-6.

40. Katoh K, Misawa K, Kuma K, Miyata T. MAFFT: a novel method for rapid multiple sequence alignment based on fast Fourier transform. Nucleic Acids Res. 2002;30:3059-66.

41. Verdoes JC, Punt PJ, Burlingame AL, Pynnonen CM, Olson PT, Wery J, Visser H, Emalfarb MA, Visser J. Chrysosporium lucknowense protein production system. WO/2010/107303. 2010.

42. Tamura K, Dudley J, Nei M, Kumar S. MEGA4: molecular evolutionary genetics analysis (MEGA) software version 4.0. Mol Biol Evol. 2007;24:1596-9.

43. Saitou N, Nei M. The neighbor-joining method: a new method for reconstructing phylogenetic trees. Mol Biol Evol. 1987;4:406-25.

\section{Submit your next manuscript to BioMed Central and we will help you at every step:}

- We accept pre-submission inquiries

- Our selector tool helps you to find the most relevant journal

- We provide round the clock customer support

- Convenient online submission

- Thorough peer review

- Inclusion in PubMed and all major indexing services

- Maximum visibility for your research

Submit your manuscript at www.biomedcentral.com/submit
() Biomed Central 